\title{
IMPLEMENTASI ALGORITMA C4.5 UNTUK MEMPREDIKSI KETERLAMBATAN PEMBAYARAN SUMBANGAN PEMBANGUNAN PENDIDIKAN SEKOLAH MENGGUNAKAN PYTHON
}

\author{
Victor Saputra Ginting ${ }^{1}$, Kusrini $^{2}$, Emha Taufiq $^{3}$ \\ Magister Teknik Informatika, Universitas Amikom Yogyakarta \\ Email : victor.ginting@ students.amikom.ac.id ${ }^{1}$, kusrini@amikom.ac.id ${ }^{2}$, \\ emhataufiqluthfi@amikom.ac.id ${ }^{3}$
}

\begin{abstract}
ABSTRAK
Sumbangan Pembangunan Pendidikan (SPP) Sekolah merupakan salah satu komponen yang penting dalam melaksanakan pendidikan, karena SPP Sekolah adalah salah satu syarat dalam mencapai tujuan pendidikan. Penelitian yang dilakukan oleh Muqorobin, 2019 dengan judul "Optimasi Metode Naive Bayes Dengan Feature Selection Gain Untuk Memprediksi Keterlambatan Pembayaran SPP Sekolah" dengan Objek Penelitian yang dilakukan di SMK Al-Islam Surakarta menghasilkan tingkat akurasi sebesar 90\%. Penelitian tersebut dilakukan dengan menggunakan beberapa variabel seperti jumlah pendapatan, tanggungan keluarga, latar belakang pendidikan orang tua dan usia orang tua. Penelitian yang akan dilakukan nantinya akan memprediksi keterlambatan pembayaran SPP Sekolah dengan menggunakan Dataset dari penelitian yang sudah dilakukan oleh Muqorobin, 2019 dan diimplementasikan kedalam bentuk pemrograman menggunakan bahasa pemrograman python untuk menghasilkan keterangan hasil prediksi. Hasil penelitian yang didapatkan mendapatkan tingkat akurasi sebesar $73 \%$.
\end{abstract}

Kata Kunci: Algoritma C4.5, Prediksi, Python, Confusion Matrix

\begin{abstract}
The Donation of Educational Development (SPP) School is one of the important components in implementing education, because School SPP is one of the requirements in achieving educational goals. Research conducted by Muqorobin, 2019 with the title "Optimization of the Naive Bayes Method with Feature Selection Gain for Predicting Late School Fee Payments" with Object Research conducted at SMK Al-Islam Surakarta resulted in an accuracy rate of $90 \%$. The research was conducted by using several variables such as the amount of income, family dependents, parents 'educational background and parents' age. The research that will be carried out later will predict the late payment of School Fees by using the Dataset from the research conducted by Muqorobin, 2019 and implemented into the form of programming using the python programming language to produce prediction results. The research results obtained get an accuracy rate of $73 \%$.
\end{abstract}

Keywords: Algorithm C4.5, Prediction, Python, Confusion Matrix 


\section{PENDAHULUAN}

Pendidikan merupakan salah satu hal yang penting bagi setiap orang. Salah satu kewajiban untuk mendapatkan pendidikan di sekolah adalah melakukan pembayaran Sumbangan Pembangunan Pendidikan (SPP) Sekolah. Tidak dapat dipungkiri, SPP Sekolah merupakan salah satu faktor penting yang digunakan untuk mealokasi biaya pembangunan sekolah, biaya untuk guru, karyawan, dan lain-lain. Biaya SPP Sekolah ini umumnya diterapkan oleh sekolah swasta yang dibebankan kepada siswanya, berbeda dengan sekolah negeri, yang biaya pengelolaan sekolah masih ada bantuan dari biaya pemerintah. Namun akan menjadi masalah yang cukup besar bagi instansi sekolah apabila keterlambatan pembayaran SPP Sekolah dilakukan oleh murid. Hal ini akan menjadi penghambat dalam mendapatkan pendidikan, khususnya di instansi sekolah swasta. Berdasarkan pemaparan diatas, perlu adanya sebuah penelitian untuk memprediksi keterlambatan pembayaran SPP Sekolah yang dilakukan murid.

Penelitian yang berjudul "Analisis Algoritma C4.5 Untuk Memprediksi Penjualan Motor Pada PT. Capella Dinamik Nusantara Cabang Muka Kuning” (Azwanti, 2018) dimana dalam penelitian tersebut menghasilkan rules yang didapat dari tiap-tiap atribut didalamnya menggunakan tools weka.

Penelitian dengan judul "Penerapan Algoritma C4.5 Pada Aplikasi Prediksi Kelulusan Mahasiswa Prodi Informatika" (Putri \& Waspada, 2018) dimana penelitian tersebut menggunakan atribut seperti asal daerah, IPK, TOEFL, dan Lama Studi menghasilkan tingkat presisi sebesar $63.93 \%$, recall $60.73 \%$, dan akurasi sebesar $60.52 \%$.
Penelitian dengan judul "Penerapan Algoritma C4.5 Untuk Memprediksi Nilai Kelulusan Siswa Sekolah Menengah Berdasarkan Faktor Eksternal" (Pambudi et al., 2018) dengan pengujian data latih dengan variabel yang berbeda menghasilkan tingkat akurasi sebesar 50\% Penelitian dengan judul "Komparasi Kinerja Algoritma C4.5 Dan Naive Bayes Untuk Prediksi Kegiatan Penerimaan Mahasiswa Baru Studi Kasus Universitas STIKUBANK Semarang" (Yahya \& Jananto, 2019) menghasilkan tingkat akurasi sebesar $87,5 \%$ menggunakan Algoritma C4.5 dan $86.6 \%$ menggunakan metode Naive Bayes.

Penelitian yang berjudul "Optimasi Metode Naive Bayes Dengan Feature Selection Information Gain untuk Prediksi Keterlambatan Pembayaran SPP Sekolah" dengan objek penelitian di SMK Al-Islam Surakarta menghasilkan keterangan prediksi yang didapatkan melalui metode naive bayes, kemudian keterangan hasil dan keterangan hasil prediksi dilakukan perbandingan dan menghasilkan tingkat akurasi sebesar 90\%. Penelitian yang akan dilakukan akan coba mengambil dataset dari penelitian oleh (Muqorobin et al., 2019) sebanyak 30 data, dengan variabel yang digunakan antara lain, penghasilan orang tua, tanggungan keluarga, pendidikan ayah, umur ayah, pendidikan ibu, umur ibu dan keterangan sebagai class, kemudian diimplementasikan kedalam sebuah pemrograman dengan menggunakan python untuk menghasilkan keterangan hasil prediksi. setelah didapatkan keterangan hasil prediksi, kemudian dilakukan perbandingan dengan keterangan hasil dengan menggunakan confusion matrix untuk mendapatkan tingkat akurasinya. 


\section{LANDASAN TEORI}

\subsection{Prediksi}

Prediksi merupakan sebuah proses dimana memperkirakan tentang sesuatu yang paling mungkin akan terjadi di masa yang akan datang berdasarkan informasiinformasi pada masa lalu atau sekarang yang dimiliki, agar kesalahan (selisih antara sesuatu yang telah terjadi dengan hasil perkiraan) dapat diperkecil. (Herdianto, 2013)

\subsection{Data Mining}

Data Mining merupakan suatu proses dimana kecerdasan buatan, matematika, teknik statistik dan machine learning digunakan untuk mengekstrasi dan mengidentifikasi informasi yang dapat bermanfaat dan pengetahuan yang terkait dari berbagai database besar (Turban, 2005). Proses Data Mining sendiri adalah sebagai berikut:

a. Data Selection

pemilihan data dari kumpulan data operasional yang dilakukan sebelum tahap penggalian informasi dalam KDD dimulai. Hasil dari seleksi data tersebut kemudian diproses, disimpan kedalam berkas terpisah dari basis data operasional

\section{b. Pre-processing/cleaning data}

Proses data mining dapat dilaksanakan, perlu dilakukan cleaning data. Proses cleaning data yakni dengan cara membuang duplikasi data, memeriksa data yang inkonsisten (missing value), dan memperbaiki kesalahan data

c. Transformation/Diskritisasi Data

Proses transformation yakni mensinambungkan atribut/variabel yang nantinya digunakan untuk memprediksi. Diskritisasi sendiri memiliki konsep hierarki, yakni mengurangi data melalui pengumpulan dan penggantian konsep level rendah(seperti nilai numerik untuk usia) dengan konsep level lebih tinggi (seperti muda, middle-aged, manula, dan lain-lain)

\section{d. Data Mining}

Data Mining merupakan proses mencari pola atau informasi menarik dalam data terpilih dengan menggunakan metode tertentu, dalam penelitian ini yakni menggunakan algoritma C4.5. Pemilihan algoritma bergantung pada tujuan dan proses KDD secara keseluruhan

\section{e. Evaluation}

Setelah mendapatkan keterangan hasil prediksi dari pemrograman python, maka dilakukan pengujian atau evaluation untuk mengukur perbandingan tingkat akurasi dari keterangan hasil dan keterangan hasil prediksi. jika tidak mendapatkan hasil yang sesuai target, maka perlu dilakukan uji coba evaluasi kembali. Proses dari Data Mining dapat dilihat pada Gambar 1.

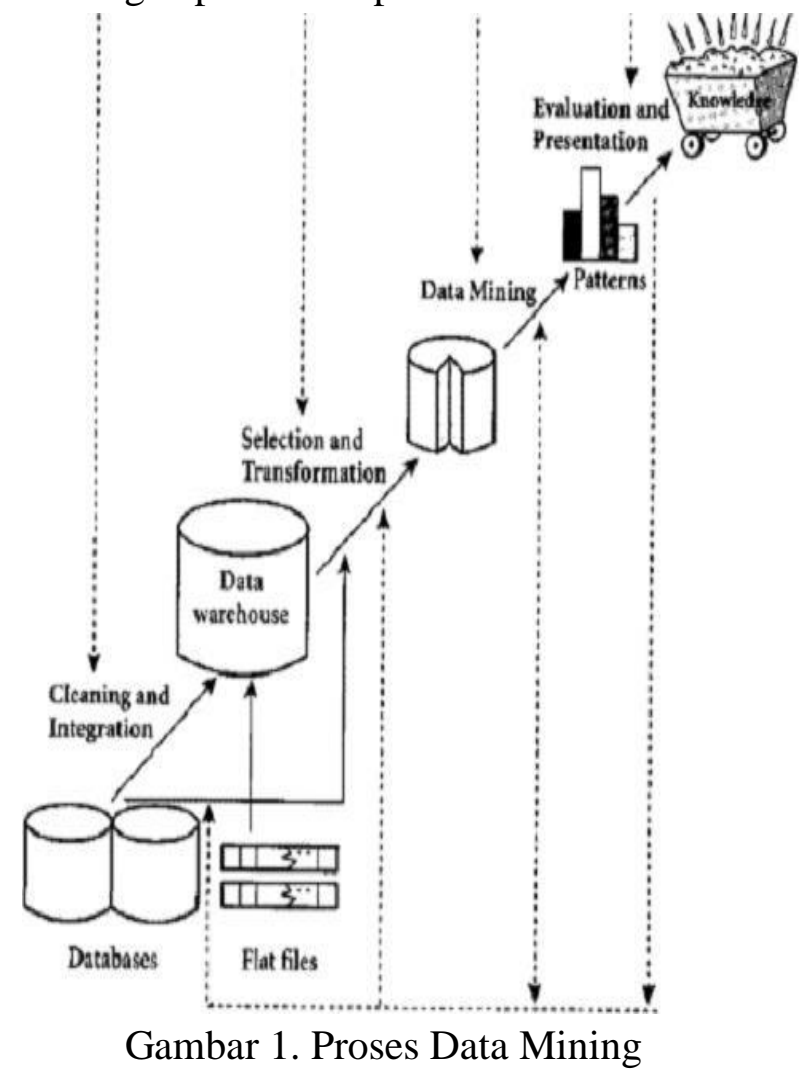




\subsection{Algoritma $\mathrm{C} 4.5$}

Algoritma Algoritma C4.5 ialah algoritma yang kegunaannya untuk membentuk pohon keputusan (Decision Tree). Pohon Keputusan sendiri merupakan metode klasifikasi dan prediksi yang cukup terkenal dan digunakan oleh banyak orang. Pohon Keputusan berguna untuk mengeksplor data dan menemukan hubungan yang tersembunyi dari variabel atau atribut yang digunakan, dan sebuah variabel target yang biasa disebut class/label. Algoritma yang sering dipakai dalam membuat pohon keputusan, yakni ID3, C4.5 dan CART. Algoritma C4.5 sendiri merupakan algoritma yang sudah dikembangkan dari algoritma ID3, dimana proses pada pohon keputusan ialah mengubah bentuk data menjadi sebuah model pohon, mengubah model pohon menjadi sebuah rules, kemudian menyederhanakan rules itu sendiri. Pembuatan Decision Tree dengan Algoritma C4.5 digunakan untuk membangun sebuah pohon keputusan yang dimulai dari pemilihan variabel atau atribut sebagai akar, membangun cabang untuk tiap nilai, membagi kasus dalam cabang kemudian melakukan pengulangan proses untuk setiap cabang sampai seluruh kasus pada cabang mempunyai kelas yang sama. Beberapa tahapan dalam Algoritma C4.5 adalah :

1. Menyiapkan data untuk dikelompokkan kedalam kelas tertentu.

2. Menentukan akar untuk dibentuk dalam pohon keputusan. Akar diambil dari variabel yang dipilih dengan cara menghitung Gain dari tiap-tiap atribut.

3. Kemudian setelah mendapatkan nilai Gain dari masing-masing variabel, maka dipilih atribut dengan nilai Gain tertinggi.

\section{Ulangi langkah hingga semua record mendapat kelas yang sama}

\subsection{Python}

Python merupakan sebuah bahasa pemrograman yang cukup terkenal yang memiliki banyak manfaat untuk mendukung pemrograman yang berorientasi objek dan dapat berjalan diberbagai macam platform sistem operasi seperti PCs, Macintosh, UNIX. Beberapa kelebihan dari bahasa pemrograman python diantara lain :

a. Pengembangan program dilakukan dengan cepat dan coding yang lebih sedikit

b. Mendukung multi platform

c. Python mudah dipelajari

d. Memiliki sistem pengelolaan memory yang otomatis

e. Python bersifat Object Oriented Programming

\subsection{Confusin Matriks}

Confusion Matrix adalah sebuah metode yang kegunaannya untuk melakukan perhitungan akurasi pada konsep dalam Data Mining. Evaluasi dengan menggunakan metode confusion matrix menghasilkan nilai akurasi, presisi dan recall. Akurasi dalam klasifikasi dalam Data Mining merupakan persentase ketepatan pada record data yang telah diklasifikasikan secara benar dan dilakukan pengujian pada hasil klasifikasi (Han et al., 2012). Presisi atau confidence merupakan proporsi pada kasus yang diprediksi positif, dimana data yang sebenarnya juga positif. Recall atau sensitivity adalah proporsi kasus positif yang diprediksi dengan benar (Abdullah et al., 2019). Pengukuran akurasi dilakukan dengan metode pengujian confusion matrix dapat dilihat dalam Tabel 1. 
Tabel 1. Confusion Matrix

\begin{tabular}{|c|c|c|}
\hline \multirow{2}{*}{$\begin{array}{c}\text { Correct } \\
\text { Classification }\end{array}$} & \multicolumn{2}{|c|}{ Classification } \\
\cline { 2 - 3 } & Positif & Negatif \\
\hline Positif & TP & TN \\
\hline Negatif & FP & FN \\
\hline
\end{tabular}

Accuracy $=\frac{\boldsymbol{T P}+\boldsymbol{T N}}{\boldsymbol{T P}+\boldsymbol{T} \boldsymbol{N}+\boldsymbol{F} \boldsymbol{P}+\boldsymbol{F N}} \times 100 \%$

Precision $=\frac{\boldsymbol{T P}}{\boldsymbol{T P}+\boldsymbol{F P}} \times 100 \%$

Recall $=\frac{\boldsymbol{T P}}{\boldsymbol{T P}+\boldsymbol{F N}} \times 100 \%$

\section{METODE PENELITIAN}

Penelitian yang akan diusulkan berjenis eksperimen. Penelitian dilakukan menggunakan dataset dari penelitian sebelumnya yang berjudul "Optimasi Metode Naive Bayes Dengan Feature Selection Gain Untuk Memprediksi Keterlambatan Pembayaran SPP Sekolah" dengan objek penelitian yang dilakukan di SMK Al-Islam Surakarta, dimana dataset yang akan digunakan berjumlah 30 . Penelitian ini terbagi menjadi beberapa bagian, yaitu Pengumpulan Data, Preprocessing. Preprocessing data dilakukan untuk mengambil data yang dibutuhkan dalam penelitian yang diusulkan. Penelitian nantinya akan diimplementasikan kedalam bentuk pemrograman menggunakan bahasa pemrograman python untuk mendapatkan keterangan hasil prediksi. pengujian dilakukan dengan menghitung nilai akurasi yang akan dihasilkan dari pemrograman, kemudian dibandingan dengan keterangan hasil dataset yang didapat. Alur penelitian dapat dilihat pada Gambar 2.

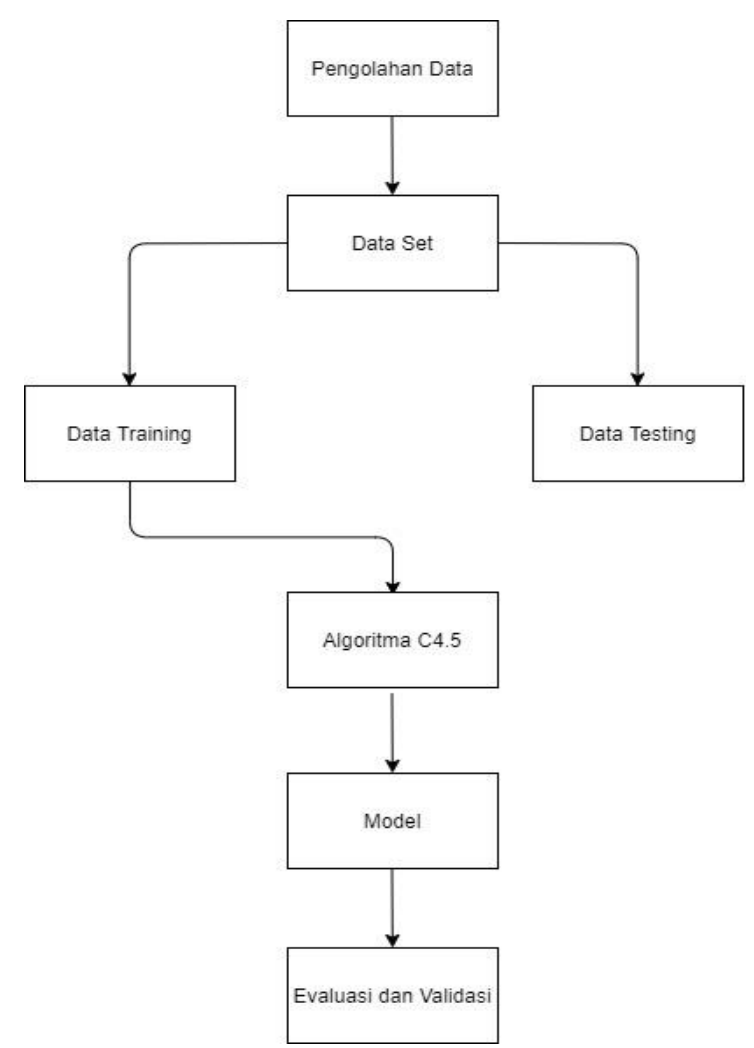

Gambar 2. Diagram Alur Penelitian

\section{HASIL DAN PEMBAHASAN}

Muqorobin menyediakan dataset yang dapat digunakan untuk tujuan penelitian dan pengembangan dengan topik memprediksi keterlambatan pembayaran SPP Sekolah. Data yang digunakan berupa tabel dan data didapat dari bagian administrasi di SMK Al-Islam dengan menggunakan atribut Penghasilan Orangtua, Tanggungan Keuarga, Pendidikan Ayah, Umur Ayah, Pendidikan Ibu, Umur Ibu, dan Keterangan sebagai class/label. Untuk dataset dapat dilihat pada Tabel 2. 
Tabel 2.

\begin{tabular}{|c|c|c|c|c|c|c|c|c|}
\hline No & Nama & $\begin{array}{c}\text { Penghasil } \\
\text { an Orang } \\
\text { Tua }\end{array}$ & $\begin{array}{c}\text { Tanggung } \\
\text { an } \\
\text { Keluarga }\end{array}$ & $\begin{array}{c}\text { Pendidi } \\
\text { kan } \\
\text { Ayah }\end{array}$ & $\begin{array}{l}\text { Umur } \\
\text { Ayah }\end{array}$ & $\begin{array}{l}\text { Pendidik } \\
\text { an Ibu }\end{array}$ & $\begin{array}{c}\text { Umur } \\
\text { Ibu }\end{array}$ & Ket \\
\hline 1 & Abdullah & 2 - 4 Juta & Cukup & SD & $\begin{array}{c}\text { Lansia } \\
\text { Awal }\end{array}$ & SMP & $\begin{array}{c}\text { Dewasa } \\
\text { Awal }\end{array}$ & Tepat \\
\hline 2 & Abu Musa & $<1$ Juta & Banyak & SD & $\begin{array}{c}\text { Lansia } \\
\text { Awal }\end{array}$ & SMP & $\begin{array}{c}\text { Lansia } \\
\text { Awal }\end{array}$ & $\begin{array}{l}\text { Terla } \\
\text { mbat }\end{array}$ \\
\hline 3 & Achmad & $1-2$ Juta & Sedikit & S1 & $\begin{array}{c}\text { Lansia } \\
\text { Awal }\end{array}$ & D3 & $\begin{array}{c}\text { Lansia } \\
\text { Awal }\end{array}$ & Tepat \\
\hline 4 & Adi Sadewo & $<1$ Juta & Cukup & SMP & $\begin{array}{l}\text { Lansia } \\
\text { Akhir }\end{array}$ & SD & $\begin{array}{l}\text { Lansia } \\
\text { Akhir }\end{array}$ & $\begin{array}{l}\text { Terla } \\
\text { mbat }\end{array}$ \\
\hline 5 & $\begin{array}{c}\text { Afifah } \\
\text { Luthfitah }\end{array}$ & $1-2$ Juta & Sedikit & SMA & $\begin{array}{c}\text { Dewasa } \\
\text { Awal }\end{array}$ & SMP & $\begin{array}{c}\text { Dewasa } \\
\text { Akhir }\end{array}$ & $\begin{array}{l}\text { Terla } \\
\text { mbat }\end{array}$ \\
\hline 6 & Afilia Nur & $<1$ Juta & Banyak & SMA & $\begin{array}{l}\text { Lansia } \\
\text { Akhir }\end{array}$ & SD & Manula & Tepat \\
\hline 7 & Agal Febri & $1-2$ Juta & Sedikit & D3 & $\begin{array}{c}\text { Dewasa } \\
\text { Awal }\end{array}$ & SMA & $\begin{array}{c}\text { Dewasa } \\
\text { Akhir }\end{array}$ & Tepat \\
\hline 8 & Ahmad Jadid & 2- 4 Juta & Cukup & SD & $\begin{array}{l}\text { Lansia } \\
\text { Akhir }\end{array}$ & D3 & $\begin{array}{c}\text { Lansia } \\
\text { Awal }\end{array}$ & $\begin{array}{l}\text { Terla } \\
\text { mbat }\end{array}$ \\
\hline 9 & Ahmad Latif & $1-2$ Juta & Sedikit & SMP & Manula & SD & Manula & $\begin{array}{l}\text { Terla } \\
\text { mbat }\end{array}$ \\
\hline 10 & $\begin{array}{l}\text { Ahmad } \\
\text { Migdad }\end{array}$ & $<1$ Juta & Cukup & SD & Manula & SMA & $\begin{array}{l}\text { Lansia } \\
\text { Akhir }\end{array}$ & Tepat \\
\hline \multicolumn{9}{|c|}{$\cdots$} \\
\hline 30 & Amelia Duwi & $>4$ Juta & Banyak & S1 & $\begin{array}{c}\text { Dewasa } \\
\text { Awal }\end{array}$ & D3 & $\begin{array}{c}\text { Dewasa } \\
\text { Akhir }\end{array}$ & Tepat \\
\hline
\end{tabular}


Dataset yang terkumpul kemudian diimpelementasikan kedalam bentuk pemrograman menggunakan Python. Dataset yang disimpan kedalam bentul excel, kemudian diubah kedalam format CSV(Comma delimeted) agar dapat diimplementasikan kedalam pemrograman.

Python yang digunakan penulis adalah Python dengan versi Python 3.8.1 dengan Framework Jupyter. Selanjutnya import library yang dibutuhkan dalam pemrograman python seperti numpy, pandas, Chefboost dan sklearn. Untuk proses coding dengan bahasa pemrograman python dapat dilihat pada Gambar 3.

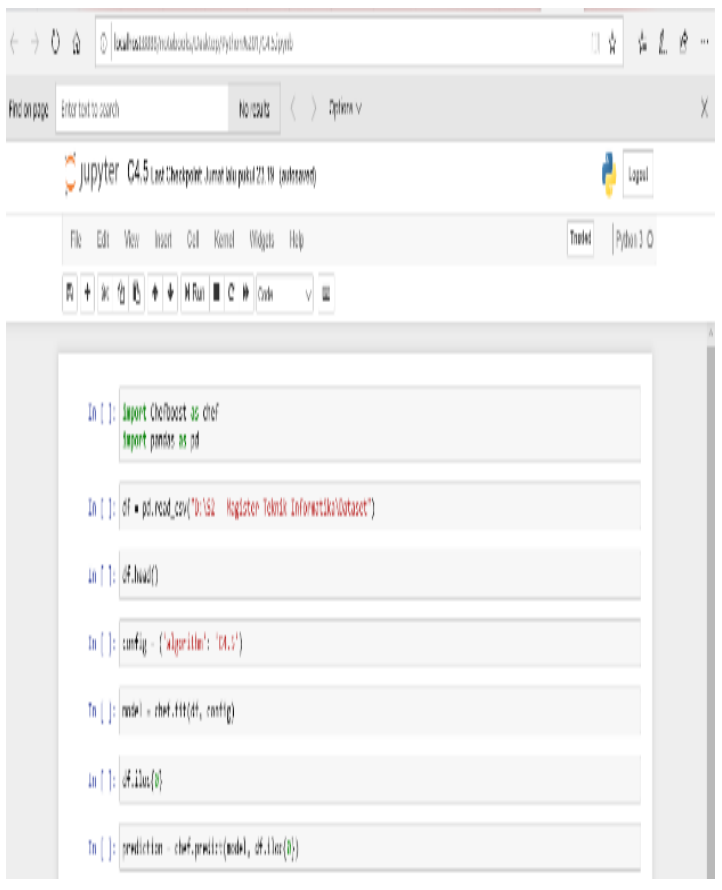

Gambar 3. Impelementasi python

Proses dataset yang telah di import ke dalam Framework, langkah selanjutnya kemudian menginputkan persamaan Algoritma C4.5. kemudian ketika program di run, keterangan hasil prediski dari pemrograman didapatkan. Hasil keterangan prediksi dapat dilihat pada Gambar 4.

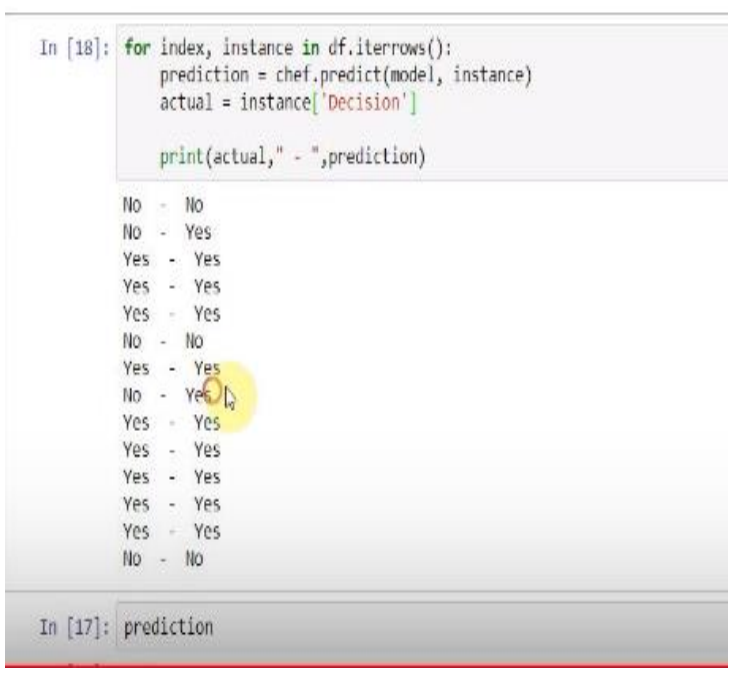

Gambar 4. Hasil Impelementasi Algoritma C4.5 Menggunakan Python

Untuk perbandingan keterangan hasil dan keterangan hasil prediksi dari dataset yang berjumlah 30, dapat dilihat pada Tabel 3.

Tabel 3. Perbandingan Keterangan Hasil dan Prediksi

\begin{tabular}{|c|c|c|}
\hline No & $\begin{array}{l}\text { Keterangan } \\
\text { Hasil Dataset }\end{array}$ & $\begin{array}{c}\text { Keterangan } \\
\text { Hasil Prediksi } \\
\text { Python }\end{array}$ \\
\hline 1 & Tepat & Tepat \\
\hline 2 & Terlambat & Terlambat \\
\hline 3 & Tepat & Terlambat \\
\hline 4 & Terlambat & Terlambat \\
\hline 5 & Terlambat & Terlambat \\
\hline 6 & Tepat & Terlambat \\
\hline 7 & Tepat & Tepat \\
\hline 8 & Terlambat & Tepat \\
\hline 9 & Terlambat & Terlambat \\
\hline 10 & Tepat & Terlambat \\
\hline 30 & Tepat & Tepat \\
\hline \multicolumn{3}{|c|}{$\begin{array}{l}\text { Confusion Matrix } \\
\text { Confusion matrix digunakan untuk } \\
\text { melakukan pengukuran tingkat akurasi dari } \\
\text { keterangan hasil dan keterangan hasil } \\
\text { prediksi yang didapat. untuk confusion } \\
\text { matrix dapat dilihat pada persamaan } 1 \\
\text { Tabel Confusion Matrix dapat dilihat pada } \\
\text { Tabel } 4 \text {. }\end{array}$} \\
\hline
\end{tabular}


Tabel 4. Pengujian Confusion Matrix

\begin{tabular}{|l|c|c|}
\hline \multirow{2}{*}{$\begin{array}{l}\text { Correct } \\
\text { Classification }\end{array}$} & \multicolumn{2}{|c|}{ Classification } \\
\cline { 2 - 3 } & Positif & Negatif \\
\hline Positif & 10 & 4 \\
\hline Negatif & 4 & 12 \\
\hline
\end{tabular}

Keterangan :

1. Classification Positif - Positif $=10$ karena jumlah data positif yang terklasifikasi dengan benar oleh sistem

2. Classification Negatif - Positif $=4$ karena jumlah data positif yang terklasifikasi dengan benar oleh sistem

3. Classification Positif - Negatif $=4$ karena jumlah data positif yang terklasifikasi dengan benar oleh sistem

4. Classification Negatif - Negatif $=12$ karena jumlah data positif yang terklasifikasi dengan benar oleh sistem

Hasil Pengujian :

Akurasi $=10+12 /(10+4+4+12) * 100 \%=$ $73 \%$

Presisi $=10 /(10+4) * 100 \%=71 \%$

Recall $=10 /(10+4) * 100 \%=71 \%$

\section{SIMPULAN DAN SARAN}

Berdasarkan hasil yang didapatkan dari keterangan hasil dan hasil prediksi dengan Algoritma C4.5, maka nilai akurasi, precision, dan recall sebesar $73 \%$, $71 \%$, dan $71 \%$.

Saran yang dapat diberikan untuk penelitian selanjutnya agar dapat dilakukan dengan menggunakan metode klasifikasi lain untuk menghasilkan tingkat akurasi yang lebih baik, melakukan perbandingan dengan metode Data Mining lainnya dan penelitian lebih lanjut mengenai atributatribut yang nantinya akan dipilih.

\section{DAFTAR PUSTAKA}

Abdullah, R. W., Kusrini, K., \& Luthfi, E. T. (2019). Prediksi Keterlambatan Pembayaran Spp Sekolah Dengan Metode K-Nearest Neighbor (Studi Kasus Smk Al-Islam Surakarta). Pemodelan Arsitektur Sistem Informasi Perizinan Menggunakan Kerangka Kerja Togaf Adm.

Azwanti, N. (2018). Analisa Algoritma C4.5 Untuk Memprediksi Penjualan Motor Pada Pt. Capella Dinamik Nusantara Cabang Muka Kuning. Informatika Mulawarman: Jurnal Ilmiah Ilmu Komputer. https://doi.org/10.30872/jim.v13i1.62 9

Han, J., Kamber, M., \& Pei, J. (2012). Data Cube Technology. In Data Mining. https://doi.org/10.1016/b9780-12-381479-1.00005-8

Herdianto. (2013). Prediksi Kerusakan Motor Induksi Menggunakan Metode Jaringan Saraf Tiruan Backpropagation. Tesis, Fakultas Teknik, Universitas Sumatera Utara.

Muqorobin, M., Kusrini, K., \& Luthfi, E. T. (2019). Optimasi Metode Naive Bayes Dengan Feature Selection Information Gain Untuk Prediksi Keterlambatan Pembayaran Spp Sekolah. Jurnal Ilmiah SINUS, 17(1), 1.

https://doi.org/10.30646/sinus.v17i1.3 78

Pambudi, R. H., Setiawan, B. D., \& Indriati. (2018). Penerapan Algoritma C4 . 5 Untuk Memprediksi Nilai Kelulusan Siswa Sekolah Menengah Berdasarkan Faktor Eksternal. Jurnal Pengembangan Teknologi Informasi Dan Ilmu Komputer.

Putri, R. P. S., \& Waspada, I. (2018). Penerapan Algoritma C4.5 pada Aplikasi Prediksi Kelulusan Mahasiswa Prodi Informatika. Khazanah Informatika: Jurnal Ilmu Komputer Dan Informatika. 
https://doi.org/10.23917/khif.v4i1.59 75

Turban. (2005). Mechine Learning untuk Mengesktraksi dan Mengidentifikasi Informasi yang bermanfaat. Mechine Learning .

Yahya, N., \& Jananto, A. (2019). Komparasi Kinerja Algoritma C.45 Dan Naive Bayes Untuk Prediksi Kegiatan Penerimaanm Mahasiswa Baru (studi kasus: Universitas Stikubank Semarang). Prosiding SENDI. 